TOLEDO, J.C. et al. Fisiopatologia da contração tônica clônica involuntária da cinomose.

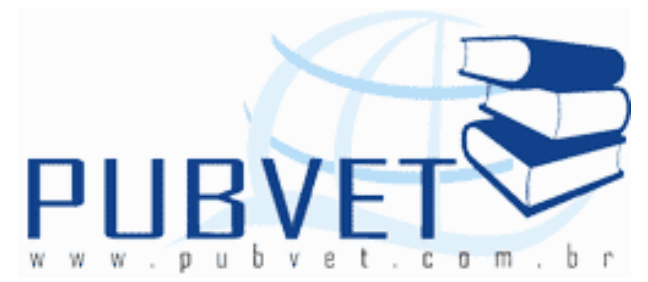

PUBVET, Publicações em Medicina Veterinária e Zootecnia.

\title{
Fisiopatologia da contração tônica clônica involuntária da cinomose
}

\author{
Juliana Capello Toledo ${ }^{1}$; Marcus Vinícius Alves da Silva ${ }^{1}$; Renata Dias \\ Rodrigues ${ }^{1}$; Rafael Rocha de Souza ${ }^{2}$.
}

${ }^{1}$ Graduandos em Medicina Veterinária. Universidade Federal de Uberlândia MG.

${ }^{2}$ Residente de Patologia Clínica Veterinária. Universidade Federal de Uberlândia - MG.

\section{Resumo}

A cinomose causada pelo vírus da cinomose canina (VCC), família Paramyxoviridae é uma doença altamente contagiosa, onde o cão representa o principal reservatório. Apresenta elevado índice de mortalidade e gera transtornos oculares, respiratórios, gastrintestinais e neurológicos, resultando em doença desmielinizante multifocal progressiva. Acometendo cães de qualquer idade, raça, sexo e maior predileção por filhotes. A cinomose pode ser diagnosticada laboratorialmente através da visualização de corpúsculos de inclusão de Lenz em esfregaços sanguíneos, no líquor e em impressões das mucosas nasal, prepucial, vaginal e principalmente conjuntival. Sua sintomatologia é diversa, e geralmente grave, tais como: transtornos psíquicos, contrações tônico-clônicas generalizadas, ataxias e mioclonias locais. Essa é caracterizada pela contração repetitiva de um músculo ou de um ou mais grupos musculares, envolvendo principalmente os músculos da 
TOLEDO, J.C. et al. Fisiopatologia da contração tônica clônica involuntária da cinomose. PUBVET, Londrina, V. 5, N. 40, Ed. 187, Art. 1263, 2011.

mastigação e apendiculares. O sinal patognomônico da doença pode ocorrer durante a fase aguda da doença, geralmente relacionada com lesão nos núcleos basais, mas é observada com maior frequência na fase crônica, relacionada com a hiperexcitabilidade dos neurônios motores inferiores, sendo relatado maior frequência de mioclonia em casos crônicos. O prognóstico para resolução da mioclonia é grave. Não há medicamentos de uso diário que controlem os sinais. Se a mioclonia for grave o animal é frequentemente sacrificado. Em casos menos graves o cão pode ser conservado como animal de estimação, mas a mioclonia geralmente persiste por vários anos.

Palavras-chave: cinomose, sintomatologia nervosa, contração tônico clônica.

\section{Pathophysiology of involuntary clonic tonic contraction distemper}

\section{Abstract}

The distemper caused by canine distemper virus (VCC), family Paramyxoviridae is a highly contagious disease, where the dog is the main reservoir. Has a high mortality rate and generates eye disorders, respiratory, gastrointestinal and neurological disorders, resulting in progressive multifocal demyelinating disease. Affects dogs of any age, race, gender and preference for pups. Distemper can be diagnosed by laboratory by viewing Lenz's inclusion corpuscles in blood smears, in CSF and impressions of the nasal mucosa, preputial, particularly vaginal and conjunctival. Its symptoms are diverse, and often severe, such as psychological disorders, tonic-clonic contractions, local myoclonus and ataxia. This is characterized by repetitive contraction of a muscle or one or more muscle groups, mainly involving the muscles of mastication and appendicular. The pathognomonic sign of the disease may occur during the acute phase of disease, usually associated with lesions in the basal ganglia, but is most frequently observed in the chronic phase, related to the hyperexcitability of the lower motor neurons, being reported more frequently in chronic cases of myoclonus. The prognosis for resolution of the myoclonus is severe. There is no medicine everyday to control the signals. If 
TOLEDO, J.C. et al. Fisiopatologia da contração tônica clônica involuntária da cinomose. PUBVET, Londrina, V. 5, N. 40, Ed. 187, Art. 1263, 2011.

the animal is severe myoclonus is often sacrificed. In less severe cases the dog may be kept as a pet, but the myoclonus usually persists for several years.

Keywords: canine distemper, nervous symptoms, tonic clonic contraction

\section{Revisão de literatura}

A Cinomose é uma doença viral altamente contagiosa (TIPOLD, 1995) causada pelo vírus da cinomose canina (VCC), ou Canine Distemper Virus, um Morbillivirus da família Paramyxoviridae (FENNER, 2004).

O cão representa o principal reservatório para o vírus da cinomose (MOLL et al. 1995). Além de cães domésticos, outros membros da família Canidae e alguns das famílias Mustelidae, Procyonidae, Hyaenidae, Ailuridae, Viverridae e Tuyussuidae, grandes felinos e primatas Cercopithecidae são suscetíveis à infecção natural pelo vírus da CC (Deem et al., 2000).

Possui elevado índice de mortalidade e geradora de transtornos oculares, respiratórios, gastrintestinais e neurológicos (GREENE, 1984). Acomete cães de qualquer idade, raça e sexo (CHRISMAN 1985, TIPOLD et al. 1992, THOMAS et al. 1993), mas tem maior predileção por filhotes (GILLESPIE 1962, APPEL 1969, KRAKOWKA \& KOESTNER 1976). Vários relatos, porém, e estudos epidemiológicos revelaram aumento na incidência da infecção por este agente tanto em cães vacinados como em não vacinados (JOZWIK e FRYMUS, 2002).

A viremia ocorre do $3^{\circ}$ ao $10^{\circ}$ dia após o contágio. Durante a primeira semana, antes do aparecimento dos sintomas, os vírus associados às células disseminam-se via sanguínea até a medula óssea, baço, timo e gânglios linfáticos, atingindo em torno de sete dias nos epitélios do estômago e intestinos, vias respiratórias e urinárias, pele e sistema nervoso central,propagando-se por todo o organismo.

Portanto trata-se de uma infecção generalizada, onde a ocorrência da multiplicação viral inicia-se nos tecidos linfóides orofaríngeos. Alguns cães desenvolvem resposta imune precoce e se recuperam rapidamente. A doença e 
TOLEDO, J.C. et al. Fisiopatologia da contração tônica clônica involuntária da cinomose. PUBVET, Londrina, V. 5, N. 40, Ed. 187, Art. 1263, 2011.

as infecções subclínicas produzem imunidade ativa e os anticorpos maternos são transmitidos aos filhotes (CATROXO, 2003).

Já os cães que não se recuperam, infectados pelo VCC desenvolvem sinais clínicos e lesões respiratórias, gastrintestinais, dermatológicas, oftalmológicas e neurológicas, que podem ocorrer sequencialmente, simultaneamente ou isoladamente (GREENE \& APPEL 2006).

Segundo Wheeler (1995), é a doença infecciosa do sistema nervoso mais comum nesta espécie. No sistema nervoso central (SNC) a cinomose está relacionada com infecção persistente pelo vírus da VCC resultando em doença desmielinizante multifocal progressiva (SCHOBESBERGER et al., 2002; VANDEVELDE, 2005).

Um estudo recente, conduzido no Laboratório de Patologia Veterinária (LPV) da Universidade Federal de Santa Maria (UFSM) (FIGHERA et al. 2008), demonstrou que encefalite por cinomose representa a principal causa de morte ou razão para eutanásia de cães necropsiados na Mesorregião do Centro Ocidental Rio-Grandense.

Os sinais neurológicos podem aparecer simultaneamente com os sinais sistêmicos, e podem surgir entre uma a três semanas após a recuperação da doença sistêmica ou podem se desenvolver na ausência de quaisquer outros sinais (KOESTNER, 1975; SUMMERS et al.,1995; VANDEVELDE; ZURBRIGGEN, 2005).

A manifestação clínica neurológica da infecção pelo vírus da cinomose canina (VCC) é muito variável, pois depende da região do sistema nervoso central (SNC) comprometida, e pode apresentar pouca correlação com a extensão da lesão no SNC. As causas para esse amplo espectro de sinais neurológicos na cinomose não são bem compreendidas (SUMMERS et al., 1984).

Sua sintomatologia é diversa, mas geralmente grave, tal como: transtornos psíquicos e alterações de comportamento, contrações tônicoclônicas

generalizadas e mioclonias locais, ataxias, paraplegias e tetraplegias, sintomas 
TOLEDO, J.C. et al. Fisiopatologia da contração tônica clônica involuntária da cinomose. PUBVET, Londrina, V. 5, N. 40, Ed. 187, Art. 1263, 2011.

cerebelares (tremores de cabeça e hipermetria) e vestibulares (cabeça pêndula, ataxia e nistagmo), movimentos de andar em círculo e "pedalar", paralisias da mandíbula, da bexiga urinária e do reto, perda da percepção sensitiva e parestesias com automutilações entre outros.

A cinomose pode ser diagnosticada laboratorialmente através da visualização de corpúsculos de inclusão de Lenz em esfregaços sanguíneos, no líquor e em impressões das mucosas nasal, prepucial, vaginal e principalmente conjuntival (GELATT, 1981; GREENE, 1984; CHRISMAN, 1991). De acordo com APPEL e CARMICHAEL (1979), o encontro destes corpúsculos de inclusão em células das conjuntivas ocular ou vaginal é sinal patognomônico de cinomose. Inclusões intracitoplasmáticas e intranucleares podem também ocorrer em neurônios, astrócitos, células das meninges e epêndima (BRAUND et al.,1987). O diagnóstico da cinomose pode ser sugerido pelo achado destes corpúsculos de inclusão no sistema nervoso (WHEELER, 1995). Na eletroencefalografia de cães com cinomose nervosa são observados traçados típicos de encefalopatia difusa e inflamatória, clássicos dessa doença (REDDING, 1987).

Em analises laboratoriais cães com cinomose apresentam leucopenia 4 a 6 dias após a infecção. Uma vez que a doença esteja instalada, observar-se-á linfopenia, monocitose e leve neutrofilia (APPEL, CARMICHAEL, 1979; FARROW, LOVE, 1983; GREENE, 1984), podendo haver leucocitose devido à infecção bacteriana secundária (JAIN, 1993).

Nos casos de encefalomielite por cinomose podem ou não apresentar alterações no líquor (SHELL, 1990). As anormalidades possíveis de serem encontradas são: aumento de proteínas (superior a $25 \mathrm{mg} / \mathrm{dl}$ ) e pleocitose (mais de 10 células $/ \mathrm{mm}^{3}$ ), com predomínio de mononucleares (GREENE, 1984; CHRISMAN, 1991; BRAUND, 1994).

Seis síndromes clínicas são descritas na cinomose: encefalomielite dos cães jovens, encefalomielite multifocal dos cães adultos, encefalite dos cães velhos (BRAUND, 1994), encefalite pós-vacinal (HARTLEY, 1974; BRAUND, 1994), encefalomielite desmielinizante crônica recidivante dos cães adultos 
TOLEDO, J.C. et al. Fisiopatologia da contração tônica clônica involuntária da cinomose. PUBVET, Londrina, V. 5, N. 40, Ed. 187, Art. 1263, 2011.

(HIGGINS et al., 1989) e polioencefalite do corpúsculo de inclusão (NESSELER et al., 1997; NESSELER et al., 1999).

Os sinais clínicos associados com lesão no diencéfalo são semelhantes aos observados nas lesões corticais e geralmente são descritos juntos como síndrome tálamo-cortical ou déficit no prosencéfalo (DEWEY, 2006). Lesões extensas no diencéfalo podem provocar estupor e coma, visto que o diencéfalo faz parte do sistema de ativação reticular ascendente, que se projeta para o córtex telencefálico e é responsável pela vigília (DEWEY, 2006). Lesões no nervo óptico ou nos núcleos geniculados laterais, que são localizados no diencéfalo, resultam em déficit visual e na resposta à ameaça (CHRISMAN, 1985; DEWEY, 2006). Sinais de lesão no hipotálamo não são muito observados em cães com cinomose (McGRATH, 1960).

Sinais neurológicos relacionados com lesão do tronco encefálico, em nível do mesencéfalo e bulbo, incluem distúrbios graves da consciência (estupor e coma) resultantes de comprometimento do sistema de ativação reticular ascendente, alterações na marcha (ataxia, paresia ou paraplegia do neurônio motor superior) (DEWEY, 2006), anisocoria e estrabismo (lesão nos núcleos dos nervos troclear ou oculomotor), atrofia muscular da cabeça (lesão no nervo trigêmeo) e não são muito freqüentes na cinomose (CHRISMAN, 1985).

A ataxia cerebral provavelmente está relacionada com lesões nas regiões mais craniais do tronco encefálico e disfunção extrapiramidal (McGRATH, 1960).

Sinais neurológicos de disfunção cerebelar são evidenciados por manifestação de movimentos exagerados (hipermetria), ataxia (do tronco e da cabeça) sem paresia, tremor de intenção, rigidez por descerebelação e déficits vestibulares (inclinação da cabeça, nistagmo, andar em círculos e estrabismo vestibular) (McGRATH, 1960; CHRISMAN, 1985; DEWEY, 2006).

Sinais de déficit nos nervos cranianos são raros, exceto para o nervo óptico, em que se observa ausência do reflexo pupilar, mesmo sem sinais óbvios de cegueira (McGRATH,1960; CHRISMAN, 1985), podendo também 
TOLEDO, J.C. et al. Fisiopatologia da contração tônica clônica involuntária da cinomose. PUBVET, Londrina, V. 5, N. 40, Ed. 187, Art. 1263, 2011.

haver cegueira secundária à neurite pela infecção pelo VCC (MCGRATH, 1960; CHRISMAN, 1985).

Automutilação pode ser observada em alguns casos de cinomose, com destruição de patas ou cauda, possivelmente devido a lesões localizadas no córtex do lobo parietal, nos feixes sensitivos do tronco encefálico e da medula espinhal (CHRISMAN, 1985). Lesões nas meninges são manifestadas por hiperestesia e, menos comumente, rigidez cervical (McGRATH, 1960; INNES; SAUNDERS, 1962), que aparecem geralmente acompanhadas por outros sinais encefálicos ou medulares (McGRATH, 1960), mas têm ocorrência rara em cães com cinomose (INNES; SAUNDERS, 1962).

Mioclonias, convulsões e ataxia são sinais frequentemente observados em cães com cinomose (McGRATH, 1960; HIGGINS et al., 1982; THOMAS et al., 1993; TUDURY et al., 1997; KOUTINAS et al., 2002; GEBARA et al., 2004; SILVA et al., 2007).

Mioclonia é caracterizada pela contração repetitiva de um músculo ou de um ou mais grupos musculares, envolvendo principalmente os músculos da mastigação e apendiculares (LORENZ; KORNEGAY, 2006).

Embora a mioclonia também tenha sido observada em outras doenças (O'BRIEN, 1981; GREENE; APPEL, 2006) e em síndromes raras que cursam com degeneração esponjosa no SNC de cães das raças Labrador Retriever, Saluki, Samoieda e Silky Terrier (LORENZ; KORNEGAY, 2006), a causa mais comum da mioclonia em cães é cinomose (TIPOLD et al., 1992; KOUTINAS et al., 2002; LORENZ; KORNEGAY, 2006) e mioclonia é considerada um sinal patognomônico por alguns pesquisadores (BREAZILE et al., 1966; TIPOLD et al., 1992).

A frequência da mioclonia é alta, variando de 40\% (TIPOLD et al., 1992) até $75 \%$ dos casos (TUDURY et al., 1997). Gemidos ou choro contínuo, interpretados como manifestações de dor, frequentemente acompanham a mioclonia (McGRATH, 1960).

Os achados bibliográficos do mecanismo das contrações tônico clônicas na cinomose ainda não são bem relatos. Estudos experimentais sugerem que 
TOLEDO, J.C. et al. Fisiopatologia da contração tônica clônica involuntária da cinomose. PUBVET, Londrina, V. 5, N. 40, Ed. 187, Art. 1263, 2011.

lesões focais na substância cinzenta da medula espinhal podem desencadear as mioclonias do pescoço, tronco e membros causadas por lesão no neurônio motor inferior; outra possibilidade é que lesões nos núcleos basais podem iniciar a mioclonia e funcionar como um marca-passo na medula espinhal ou no tronco encefálico (para as mioclonias localizadas na cabeça), mantendo o movimento muscular involuntário (CHRISMAN, 1985; SUMMERS et al., 1995). As mioclonias persistem mesmo durante o sono (CHRISMAN, 1985).

A mioclonia na cinomose pode ocorrer durante a fase aguda da doença, geralmente relacionada com lesão nos núcleos basais, mas é observada com maior frequência na fase crônica, relacionada com a hiperexcitabilidade dos neurônios motores inferiores (LORENZ; KORNEGAY, 2006). Maior frequência de mioclonia em casos crônicos também foi observada por outros autores (MaciNTYRE et al., 1948). É possível que as mioclonias dos músculos temporais estejam relacionadas com lesões no nervo trigêmeo (McGRATH, 1960).

Em um estudo foi relatado que as mioclonias cessam com a estimulação elétrica do córtex motor frontal contralateral, pedúnculos cerebelares e pirâmides (McGRATH, 1960).

Convulsões são muito comuns na cinomose, geralmente descritas como convulsões de "goma de mascar" ou de "tique de mastigação", em que o cão movimenta ativamente a mandíbula acompanhada por espasmos de grupos musculares e salivação abundante (McGRATH, 1960). Muitas vezes, convulsões parciais graves progridem para convulsões tônico-clônicas generalizadas, e são associadas com lesão no lobo temporal e piriforme (McGRATH, 1960). Em alguns casos, convulsão é o único sinal clínico observado (MacINTYRE et al., 1948; CHRISMAN, 1985).

Os achados bibliográficos do mecanismo das contrações tônico clônicas na cinomose ainda não é bem relato. Estudos experimentais sugerem que lesões focais na substância cinzenta da medula espinhal podem desencadear as mioclonias do pescoço, tronco e membros causadas por lesão no neurônio motor inferior; outra possibilidade é que lesões nos núcleos basais podem 
TOLEDO, J.C. et al. Fisiopatologia da contração tônica clônica involuntária da cinomose. PUBVET, Londrina, V. 5, N. 40, Ed. 187, Art. 1263, 2011.

iniciar a mioclonia e funcionar como um marca-passo na medula espinhal ou no tronco encefálico (para as mioclonias localizadas na cabeça), mantendo o movimento muscular involuntário (CHRISMAN, 1985; SUMMERS et al., 1995). As mioclonias persistem mesmo durante o sono (CHRISMAN, 1985).

A mioclonia na cinomose pode ocorrer durante a fase aguda da doença, geralmente relacionada com lesão nos núcleos basais, mas é observada com maior frequência na fase crônica, relacionada com a hiperexcitabilidade dos neurônios motores inferiores (LORENZ; KORNEGAY, 2006). Maior frequência de mioclonia em casos crônicos também foi observada por outros autores (MacINTYRE et al., 1948).

É possível que as mioclonias dos músculos temporais estejam relacionadas com lesões no nervo trigêmeo (McGRATH, 1960).

Os grupos musculares mais comumente afetados são os dos membros, os temporais e os masseteres na cabeça.

Em um estudo foi relatado que as mioclonias cessam com a estimulação elétrica do córtex motor frontal contralateral, pedúnculos cerebelares e pirâmides (McGRATH, 1960).

O prognostico para resolução da mioclonia é grave. Não há medicamentos de uso diário que controlem os sinais. Se a mioclonia for grave o animal é frequentemente sacrificado. Em casos menos graves o cão pode ser conservado como animal de estimação, mas a mioclonia geralmente persiste por vários anos.

\section{REFERÊNCIAS}

APPEL M.J.G. Pathogenesis of canine distemper. American Journal Veterinary Research. n.30, p.1167-1182, 1969.

APPEL, M.J., CARMICHAEL, L.E. Systemic viral diseases. In: CATCOTT, E.J. Canine Medicine. 4. ed. Santa Barbara: American Veterinary Publications, p. 17-48, 1979.

BRAUND, K.G. Clinical syndromes in veterinary neurology. 2. ed. St. Louis: Mosby, 1994. $477 \mathrm{p}$.

BRAUND, K. G.; CRAYLEY, R. R.; SPEAKMEN, C. Hippocampal necrosis associated with canine distemper virus infection. Veterinary Record, v. 109, n. 6, p. 122-123, 1981. 
BREAZILE, J. F.; BLAUGH, B. S.; NAIL, N. Experimental study of canine distempermyoclonus. American Journal of Veterinary Research, v. 27, n. 120, p. 1375-1379, 1966.

CATROXO, M.H.B . Cinomose Canina- Divulgação Técnica. Biológico, São Paulo, v.65, n.1, p.1-2, 2003.

CHAPPUIS G. Control of canine distemper. Veterinary Microbiology, n.4, p.351-358, 1995

CHRISMAN C.L. Neurologia dos Pequenos Animais. Roca, São Paulo. 432p. 1985.

CHRISMAN, C.L. Problems in small animal neurology. 2. ed. Philadelphia: LEA \& FEBIGER, 1991. 526 p.

DEWEY, C. W. Neuroanatomia functional e não funcional: a chave para a localização da lesão. In: DEWEY, C. W. (Org) Neurologia de cães e gatos. Guia prático. São Paulo: Roca, 2006. cap. 1 , p. 1-18.

FARROW, B.R.H., LOVE, D.N. Bacterial, viral and other infectious problems. In: ETTINGER, S.J. Textbook of veterinary internal medicine. Diseases of the dog and cat. 2 . ed.

Philadelphia: Saunders, 1983. Cap. 27. p. 269-319.

FENNER W.R. 2004. Doenças do cérebro, p.586-638. In: ETTINGER S.J. \& FELDMAN E.C. (Eds), Tratado de Medicina Interna Veterinária: doenças do cão e do gato. v.1. $4^{\mathrm{a}}$ ed. Guanabara Koogan, Rio de Janeiro. 1038p.

FIGHERA R.A., SOUZA T.M., SILVA M.C., BRUM J.S., GRAÇA D.L., KOMMERS G.D., IRIGOYEN L.F. \& BARROS C.S.L. Causas de morte e razões para eutanásia de cães da Mesorregião do Centro Ocidental Rio-Grandense (1964-2004). Pesquisa Veterinária Brasileira, n.28, p.223230,2008

GEBARA, C. M. S. et al. Lesões histológicas no sistema nervoso central de cães com encefalite e diagnóstico molecular da infecção pelo vírus da cinomose canina. Arquivo Brasileiro de Medicina Veterinária e Zootecnia, v. 56, n. 2, p. 168-174, 2004.

GELATT, K.N. Textbook of veterinary ophtalmology. Philadelphia: LEA \& FEBIGER, 1981. $788 \mathrm{p}$.

GILLESPIE J.H.; RICKARD C.G. Encephalitis in dogs produced by distemper virus. American Journal Veterinary Research, n.17, p.103-108, 1956

GREENE, C.E. Clinical microbiology and infectious disease of the dog and cat. Philadelphia: Saunders, 1984, 967 p.

GREENE, C. E.; APPEL, M. J. Canine distemper. In: GREENE, C. E. (Org.) Infectious diseases of the dog and cat. 3th ed. St. Louis: Saunders Elsevier, 2006. cap. 3, p. 25-41.

HARTLEY, W. J. A post-vaccinal inclusion body encephalitis in dogs. Veterinary Pathology, v. 11, n. 4, p. 301-312, 1974.

HIGGINS, R. J.; CHIL, G.; VANDEVELDE, M. Chronic relapsing demyelinatingencephalomyelitis associated with persistent spontaneous canine distemper virus infection. Acta

Neuropathologica, New York, v. 77, n. 4, p. 441-444, 1989. 
INNES, J. R. M.; SAUNDERS, L. Z. Viral and rickettsial encephalomyelitides. In: INNES, J. R.M.; SAUNDERS, L. Z. Comparative neuropathology. New York: Academic Press, 1962. cap.8, p. 337-450.

JAIN, N.C. Essentials of veterinary hematology. Philadelphia: Lea \& Febiger, 1993. 417 p.

JOZWIK, A.; FRYMUS T. Natural distemper in vaccinated and unvaccinated dogs in Warsaw.

Journal. Veterinary. Medicine, v.49, p.413-414, 2002.

KOUTINAS, A. F. et al. Relation of clinical to pathological changes in 19 cases of

caninedistemper encephalomyelitis. Journal of Comparative Pathology, v. 126, n. 1, p. 4756, 2002.

KRAKOWKA S. \& KOESTNER A. Age-related susceptibility to infection with canine distemper virus in gnotobiotic dogs. Journal Infection, n.134, p.629-632. 1976

LORENZ, M. D.; KORNEGAY, J. N. Neurologia veterinária. 4. ed. São Paulo: Manole, 2006.467 p.

MAIA, O. B.; GOUVEIA, A. M. G. Birth and mortality of maned wolves Chrysocyon brachyurus (Illiger, 1811) in captivity. Brazilian Journal of Biology, v. 62, n. 1, p. 25-32, 2002.

MacINTYRE, A. B.; TREVAN, D. J.; MONTGOMERIE, R. F. Observations on canine encephalitis. Veterinary Record, v. 60, n. 49, p. 635-648, 1948.

McCARTHY, A. J.; SHAW, M.; GOODMAN, S. J. Pathogen evolution and diseases emergence in carnivores. Proceedings. Biological Sciences/The Royal Society. Section B, v.274, n. 1629, p. 3165-3174, 2007.

McGRATH, J. D. Inflammatory and infectious diseases. In: McGRATH, J. D. The neurologic examination of the dog with clinic-pathological observations. 2nd ed. Philadelphia: Lea \&Febiger, 1960. cap. 12, p. 123-147.

MOLL P., ALLDINGER S., BAUMGÄRTNER W.; ADAMI M. Distemper in wild carnivores: An epidemiological, histological and immunocyto-chemical study. Veterinary Microbiology, n.44, p.193-199, 1995

NESSELER, A. et al. Restricted virus protein translation in canine distemper virus inclusion body polioencephalitis. Veterinary Microbiology, v. 69, n. 1-2, p. 23-28, 1999.

O'BRIEN, D. P. Lead toxicity in a dog. Journal of the American Animal Hospital Association, v. 29, p. 845-847, 1981

REDDING, W.R. Electrophysiologic diagnosis. In: OLIVER, J.E., HOERLEIN, B.F., MAYHEW, I.G. Veterinary neurology. Philadelphia: Saunders, 1987. Cap. 5, p. 111- 184.

SHELL, L.G. Canine distemper. Compendium on Continuing Education. Small Animal Practice, v. 12, n. 2, p. 173-179, 1990.

SCHOBESBERGER, M. Demyelination precedes oligodendrocytes loss in canine distemper virus-induced encephalitis. Acta Neuropathologica, v. 103, n. 1, p. 11-19, 2002.

SILVA, M. C. et al. Aspectos clinicopatológicos de 620 casos neurológicos de cinomose em cães. Pesquisa Veterinária Brasileira, v. 27, n. 5, p. 215-220, 2007. 
SOBRINO, R. et al. Prevalence of antibodies against canine distemper virus and canine parvovirus among foxes and wolves from Spain. Veterinary Microbiology, v. 126, n. 1-3, p. 251-256, 2008.

THOMAS W.B., SORJONEM D.C.; STEISS J.E. A retrospective evaluation of 38 cases of canine distemper encephalomyelitis. Journal American Animal Hospital Associotion, n.29, p.129133,1993

THOMAS, W. B.; SORJONEN, D. C.; STEISS, J. E. A retrospective evaluation of 38 cases of canine distemper encephalomyelitis. Journal of the American Animal Hospital Association, v. 29, p. 129-133, 1993.

TIPOLD A., VANDEVELDE M.; JAGGY A. Neurological maninfestations of canine distemper virus infection. Journal Small Animal Practice, n.33, p.466-470, 1992.

TIPOLD, A. Diagnosis of inflamatory and infectious diseases of the central nervous system in dogs: a retrospective study. Journal of Veterinary Internal Medicine, v.9, p.304-314, 1995.

TUDURY, E. A. et al. Observações clínicas e laboratoriais em cães com cinomose nervosa.Ciência Rural, v. 27, n. 2, p. 229-235, 1997.

VANDEVELDE, M.; ZURBRIGGEN, A. Demyelination in canine distemper virus infection: a review. Acta Neuropathologica, v. 109, n. 1, p. 56-68, 2005.

WHEELER, S..J. Manual of small animal neurology. Gloucestershire: British Small Animal Veterinary Association, 1995.256 p. 